\title{
Adsorption and Thermal Chemistry of Formic Acid on Clean and Oxygen-Predosed Cu(110) Single-Crystal Surfaces Revisited
}

\author{
Yunxi Yao and Francisco Zaera* \\ Department of Chemistry, University of California, Riverside, CA 92521, USA \\ Email: zaera@ucr.edu
}

\begin{abstract}
The thermal chemistry of formic acid on clean and oxygen-predosed $\mathrm{Cu}(110)$ single-crystal surfaces was studied under ultrahigh-vacuum (UHV) conditions by temperature programmed desorption (TPD) and X-ray photoelectron spectroscopy (XPS). Key results reported in the past were confirmed, including the partial switchover from $\mathrm{H}_{2}$ to $\mathrm{H}_{2} \mathrm{O}$ desorption upon oxygen addition on the surface and the development of a second decomposition regime at $420 \mathrm{~K}$, in addition to the one observed at $460 \mathrm{~K}$ on the clean substrate. In addition, new observations were added, including the previously missed desorption of $\mathrm{H}_{2}$ at $420 \mathrm{~K}$ and the existence of a normal kinetic isotope effect in both TPD peaks. Peak fitting of the XPS data afforded the identification of an asymmetric geometry for the formate intermediate, which was established to form by 200 $\mathrm{K}$, and the presence of coadsorbed molecular formic acid up to the temperatures of decomposition, probably in a second layer and held by hydrogen bonding. Quantitative analysis
\end{abstract}


of the TPD data indicated a one-to-one correspondence between the increase in oxygen coverage beyond $\theta_{\mathrm{O}}=0.5 \mathrm{ML}$ and a decrease in formic acid uptake that mainly manifests itself in a decrease in the decomposition seen in the $460 \mathrm{~K}$ TPD peak. All these observations were interpreted in terms of a simple decomposition mechanism involving hydrogen abstraction from adsorbed formate species, possibly aided by coadsorbed oxygen, and a change in reaction activation energy as a function of the structure of the oxygen overlayer, which reverts from a O$\mathrm{c}(6 \times 2)$ structure at high oxygen coverages to the $\mathrm{O}-(2 \mathrm{x} 1)$ order seen at $\theta_{\mathrm{O}}=0.5 \mathrm{ML}$.

Keywords: Formic Acid, Copper Single-Crystal Surface, Predosed Oxygen, Thermal Chemistry, X-Ray Photoelectron Spectroscopy.

\section{Introduction}

Because formic acid, or most likely formate moieties, are likely intermediates in several catalytic reactions such as $\mathrm{CO}$ and $\mathrm{CO}_{2}$ hydrogenation to methanol $[1 ; 2]$, methanol steam reforming [3; 4], and water-gas shift [5-8], its surface chemistry has been investigated extensively in the past [9]. Reactivity on copper surfaces, on $\mathrm{Cu}(110)$ substrates in particular, has been probed with a number of surface-science techniques, including temperature-programmed desorption (TPD) [10-16], X-ray and ultraviolet photoelectron spectroscopies (XPS and UPS) [11;12;14;15;17], X-ray absorption spectroscopies (SEXAFS and NEXAFS) [17; 18], vibrational spectroscopies (RAIRS and HREELS) [19-25], scanning tunneling microscopy (STM) [13; 24; 26-33], lowenergy electron diffraction (LEED) [13], and molecular beams $[13 ; 15 ; 16 ; 21 ; 30 ; 31]$, and also 
theoretically by using DFT calculations $[17 ; 24 ; 34-36]$. Much has been established about the chemistry of formic acid on both clean and oxygen-predosed $\mathrm{Cu}(110)$ surfaces, but some questions still remain. Thanks to an interesting application of formic acid as a co-reactant in the atomic layer deposition (ALD) [37] of copper films recently advanced by the Winter group [3840], there is a renewed interest in settling the unresolved issues associated with this system.

Much discussion has been published on the mechanism by which formic acid decomposes thermally on oxygen-covered $\mathrm{Cu}(110)$ surfaces. A new desorption feature develops in the TPD spectra at approximately $420 \mathrm{~K}$, non existing on the clean $\mathrm{Cu}(110)$ surface, but the reported absence of $\mathrm{H}_{2}$ production at the same time (perhaps because of a lack of sensitivity in the detection of that species in the TPD experiments) has made the interpretation of those data difficult. Madix and co-workers originally suggested that the new low-temperature $\mathrm{CO}_{2}$ TPD feature originate from a new bidentate form of a formate surface intermediate, adsorbed on a different adsorption site from the more stable species intermediate that produces both $\mathrm{CO}_{2}$ and $\mathrm{H}_{2}$ at higher temperatures (about $460 \mathrm{~K}$ ) [11]. However, that idea could not explain the absence of hydrogen desorption in the first peak. For that, Campbell and co-workers suggested a disproportionation step, $2 \mathrm{HCO}_{2}($ ads $) \rightarrow \mathrm{HCOOH}(\mathrm{g})+\mathrm{CO}_{2}(\mathrm{~g})$ [12]. Unfortunately, in their experiments those authors were not able to observe the required coincident desorption of formic acid that would be produced with the $\mathrm{CO}_{2}$. Davies and co-workers proposed the formation of a carbonate species [14], but, again, no direct experimental evidence was provided to support that claim. In our work, we report a few new pieces of evidence to add to this discussion, including: (1) the detection of the missing $420 \mathrm{~K} \mathrm{H}_{2} \mathrm{TPD}$ feature not previously seen and required to understand the decomposition of formic acid in this low-temperature regime on the oxygen- 
covered $\mathrm{Cu}(110)$; and (2) the identification of a kinetic isotope effect between $\mathrm{HCOOH}$ and DCOOD. By careful analysis of our TPD and XPS data involving integration of the areas of the individual TPD peaks and curve fitting of the XPS traces, we are able to provide stoichiometric arguments and to further discuss the potential validity of the different mechanisms proposed for the formic acid decomposition. We focus on the high-coverage range of preadsorbed oxygen, above half a monolayer. More details of the results and interpretation of our work follow.

\section{Experimental Details}

All the experiments reported here were performed in an ultrahigh vacuum (UHV) chamber described elsewhere $[41 ; 42]$, a stainless-steel chamber turbopumped to a base pressure in the low $10^{-10}$ Torr range and equipped with an Extrel quadrupole mass spectrometer for the TPD experiments and a 50-mm radius VSW hemispherical electron-energy analyzer and an aluminum anode $(\mathrm{h} v=1486.6 \mathrm{eV})$ for the $\mathrm{X}$-ray studies. $\mathrm{A} \mathrm{Cu}(110)$ single crystal, a disk $10 \mathrm{~mm}$ in diameter and $1 \mathrm{~mm}$ in thickness, was mounted on a concentric manipulator by using thin tantalum wires wedged into slots on its sides and fixed to the ends of copper vacuum feedthroughs, in an arrangement that afforded cooling to $\sim 80 \mathrm{~K}$ and resistively heating to up to $1100 \mathrm{~K}$. The temperature was measured by using a K-type thermocouple wedged into a hole drilled on the side of the crystal, and controlled by using a homemade proportional-integralderivative (PID) circuit. 
For the TPD experiments, the ionizer of the mass spectrometer is contained within a cylindrical box terminated in a 7-mm-diameter aperture, which is placed in front of the crystal to selectively sample the gases desorbed from the front surface. The spectrometer is interfaced to a personal computer to afford following the evolution of the signals of up to 15 different masses in a single TPD run. A constant heating rate of $5 \mathrm{~K} / \mathrm{s}$ was employed. With respect to the XPS experiments, the electron-energy analyzer was set to a $50-\mathrm{eV}$ constant pass energy for an overall resolution of approximately $1.5 \mathrm{eV}$ FWHM; peak positions could be determined with an accuracy of approximately $0.1 \mathrm{eV}$. The raw XPS data were deconvoluted using Gaussian functions.

The surface of the crystal was cleaned before each TPD or XPS experiment by sequential cycles of $\mathrm{Ar}^{+}$ion sputtering and annealing until deemed clean by XPS. The formic acid was purchased from Sigma-Aldrich (reagent grade, $\geq 95 \%$ purity), and distilled in situ in the gas manifold via a sequence of freeze-pump-thaw cycles before use. Oxygen gas was purchased from Liquid Carbonic (Research Purity, $>99.995 \%$ ) and used as supplied. Dosing of the sample was done by backfilling of the chamber using leak valves, and is reported in Langmuirs $\left(1 \mathrm{~L}=1 \times 10^{-6}\right.$ Torr sec), uncorrected for differences in ion gauge sensitivities. The pressure in the main UHV chamber was measured by using a nude ion gauge.

\section{Results}

We started our investigation of the thermal chemistry of formic acid adsorbed on $\mathrm{Cu}(110)$ surfaces by carrying out survey TPD experiments for many ion fragments in the mass 
spectrometer in order to identify the main products and reaction temperature ranges. An example of the type of traces obtained from that work is provided in Figure 1, in this case for 2.0 $\mathrm{L}$ of $\mathrm{HCOOH}$ dosed at $190 \mathrm{~K}$ on the clean surface, sufficient to saturate the first monolayer. The data are consistent with the many previous TPD results reported in the literature [10-16]. The only products detected in this case were hydrogen (2 amu), $\mathrm{CO}_{2}(44 \mathrm{amu})$, and molecular $\mathrm{HCOOH}$ (46 amu) (and $\mathrm{H}_{2} \mathrm{O}, 18 \mathrm{amu}$, in the O-precovered surfaces), and the signals seen in the $12,16,28$ and 45 amu traces determined to originate from fragmentation of the main products in the mass spectrometer. Molecular hydrogen desorption is split almost evenly in two stages, in peaks with maxima around 350 and $465 \mathrm{~K} . \mathrm{CO}_{2}$ production is only detected in the hightemperature regime, in a TPD feature that exhibits the same leading edge of the corresponding $\mathrm{H}_{2}$ peak but that peaks at a slightly lower temperature, $\sim 460 \mathrm{~K} . \mathrm{HCOOH}$ molecular desorption from the monolayer occurs primarily in a broad temperature range between 200 and $350 \mathrm{~K}$, but a second TPD feature is also seen at $460 \mathrm{~K}$ with the same shape as that of the $\mathrm{CO}_{2}$ signal.

The evolution of this thermal chemistry as a function of the coverage of atomic oxygen $\left(\theta_{0}\right)$ on the $\mathrm{Cu}(110)$ surface is indicated by the TPD reported in Figure 2. Four panels are shown there, for the four main products, and traces are reported for the following oxygen coverages (as determined by integration of the corresponding O 1s XPS signals): $\theta_{\mathrm{O}}=0.00$ (clean), 0.40 (prepared by exposing the surface to $30 \mathrm{~L} \mathrm{O}_{2}$ at $\left.300 \mathrm{~K}\right), 0.52\left(300 \mathrm{~L} \mathrm{O}_{2}\right.$ at $\left.500 \mathrm{~K}\right), 0.56(3000 \mathrm{~L}$ $\mathrm{O}_{2}$ at $\left.500 \mathrm{~K}\right)$, and $0.62\left(6000 \mathrm{~L} \mathrm{O}_{2}\right.$ at $\left.500 \mathrm{~K}\right) \mathrm{ML}$, where a monolayer is defined as the same number of adsorbed atoms or molecules as one $\mathrm{Cu}$ layer in the $\mathrm{Cu}(110)$ clean surface $(1 \mathrm{ML}=$ $1.085 \times 10^{15}$ atoms $/ \mathrm{cm}^{2}$ ). Several trends become clearly apparent: (1) the low-temperature (350 K) $\mathrm{H}_{2}$ TPD peak disappears upon the addition of oxygen to the surface; (2) that is accompanied 
by the evolution of significant amounts of water, at about $250 \mathrm{~K}$ as well as in the hightemperature range where the other products are detected; (3) in addition to the chemistry seen around $460 \mathrm{~K}$ on clean $\mathrm{Cu}(110)$, a second set of peaks develop for all $\mathrm{H}_{2}, \mathrm{H}_{2} \mathrm{O}, \mathrm{CO}_{2}$, and $\mathrm{HCOOH}$ at $420 \mathrm{~K}$; and (4) the two main temperatures for this surface chemistry do not change significantly with oxygen coverage. All these observations have been reported before [10-16], with the one glaring and very important exception of the new distinct and easy to identify peak for $\mathrm{H}_{2}$ evolution at $420 \mathrm{~K}$, which is seen here for all oxygen coverages above $\theta_{\mathrm{O}}=0.4 \mathrm{ML}$. This is a critical new observation, because the absence of such feature in their data led Campbell and coworkers to propose the disproportionation of formic acid as the mechanism to explain the 420 K TPD peaks [12].

Similar TPD experiments as a function of $\theta_{\mathrm{O}}$ were carried out with DCOOD. The $\mathrm{D}_{2}(4 \mathrm{amu})$, $\mathrm{D}_{2} \mathrm{O}(20 \mathrm{amu}), 28 \mathrm{amu}$, DCOOD $(48 \mathrm{amu})$ and $\mathrm{CO}_{2}(44 \mathrm{amu})$ TPD traces obtained after $2.0 \mathrm{~L}$ DCOOD doses on $\mathrm{Cu}(110)$ with oxygen coverages of $\theta_{\mathrm{O}}=0.00$ (clean $\mathrm{Cu}(110)$, left panel), 0.50 $\left(200 \mathrm{~L} \mathrm{O}_{2}\right.$ at $500 \mathrm{~K}$, center), and $0.67\left(10000 \mathrm{~L} \mathrm{O}_{2}\right.$ at $500 \mathrm{~K}$, right) $\mathrm{ML}$ are shown in Figure 3 and contrasted with similar data for $\mathrm{HCOOH}$ (displayed with lighter traces). The same products are seen in this case, with the appropriate deuterium substitutions, with the shapes and relative areas of the individual TPD peaks matching the data obtained with the light reactant $(\mathrm{HCOOH})$, except for a variation between the relative yields of hydrogen versus water. There seems to also be some $\mathrm{HCOOH}$ and/or $\mathrm{DCOOH}$ produced in these experiments (data not shown), possibly because of H-D exchange with either water or hydrogen from the background. What is significant from these data is that both set of TPD peaks shift considerably to higher temperatures with deuterium substitution, from 420 and $460 \mathrm{~K}$ (as cited above) to approximately 
440 and $485 \mathrm{~K}$, respectively. It would appear that all the reactions rate limiting steps that lead to the evolution of the gas-phase products involve such deuterium atoms.

In Figure 4 we summarize the results from quantitative analysis of the TPD data. The areas under each individual peak were used to estimate the corresponding yields. Data are shown for the overall yields of each compound $\left(\mathrm{CO}_{2}, \mathrm{H}_{2}\right.$, and $\mathrm{H}_{2} \mathrm{O}$, left panel) as well as for the two individual major TPD peaks, and 420/440 (Low-T, center) and 460/485 (High-T, right) K. The mass spectrometer signals were calibrated and converted into units of monolayers as follows: the coverages of the formic acid at $200 \mathrm{~K}$ (total) and of formate species on the clean surface, obtained after flashing the adsorbed formic acid to $350 \mathrm{~K}$, were set to $\theta_{\mathrm{HCOOHads}} \sim 0.65$ and $\theta_{\mathrm{HCOOads}} \sim 0.25 \mathrm{ML}$, respectively, following previous literature estimates $[11 ; 12 ; 14 ; 15 ; 19]$, and the water yields were estimated from the O 1s XPS signals (see below), referenced to the $\theta_{\mathrm{O}}$ $=0.50 \mathrm{ML} \mathrm{O} / \mathrm{Cu}(110)$ surface. These assumptions resulted in reasonable values for all data, and afforded good mass balance at all oxygen coverages.

The trends in TPD yields versus $\theta_{\mathrm{O}}$ for the thermal decomposition of formic acid adsorbed on oxygen-precovered $\mathrm{Cu}(110)$ surfaces reported in Figure 4 are somewhat complex, and perhaps obscured in part by experimental errors and kinetic isotope effects (when comparing data from $\mathrm{HCOOH}$, solid symbols, versus DCOOD, open symbols), but a number of observations are nevertheless quite evident. In fact, these data has provided us with most of the information required for a detailed discussion of the mechanism of the decomposition of formic acid on these oxygen-treated $\mathrm{Cu}(110)$ surfaces, which we will defer to the Discussion section. 
The nature of the surface species formed upon thermal activation of formic acid adsorbed on the $\mathrm{Cu}(110)$ surface was probed by XPS. Figure 5 display the data obtained for $\mathrm{HCOOH}$ adsorbed on clean $\mathrm{Cu}(110)$ : the left panel shows the raw spectra and the fits obtained using two Gaussian peaks, and the right panel summarizes the carbon coverages on the surface as a function of annealing temperature, estimated from the areas of the fitted peaks. The parameters used in the analysis, namely, the binding energies (BE) and full-width-at-half-maximum (FWHM, or $\Delta$ ), are reported in Table 1. These data are in general consistent with those reported in previous publications $[11 ; 12 ; 14]$. The spectrum obtained at low temperature $(150 \mathrm{~K})$ displays a main broad peak that we fitted to a single feature centered around $289.6 \mathrm{eV}$, with a total signal corresponding to approximately $0.45 \mathrm{ML}$, and an additional minority peak at $286.6 \mathrm{eV}$, with an intensity equivalent to $0.1 \mathrm{ML}$. The latter indicates the formation of some formate species on the surface already (via deprotonation) at such low temperatures.

Heating to $200 \mathrm{~K}$ leads to the desorption of much of the molecularly adsorbed formic acid, as already indicated by the TPD data in Figures 1 to 4, and results in a C 1s XPS with two features at approximately 287.5 and $289.6 \mathrm{eV}$, which correspond to the formate surface species and molecular formic acid, respectively. These two features exhibit an intensity ratio of approximately $2: 1$, and correspond to a total coverage of approximately $0.38 \mathrm{ML}$, constant in the temperature range from 200 to close to $400 \mathrm{~K}$. Three observations are worth highlighting: (1) there is approximately $0.13 \mathrm{ML}$ of molecular $\mathrm{HCOOH}$ adsorbed on the surface up to about 400 $\mathrm{K}$, at which point the TPD data indicate the start of the main decomposition pathways; (2) the peak for the molecular formic acid shifts to higher binding energy, from 289.6 to $290.1 \mathrm{eV}$, between 250 and $300 \mathrm{~K}$, as the first $\mathrm{H}_{2}$ TPD desorption is seen, suggesting that the coadsorbed 
hydrogen atoms may affect the binding of the molecular species; and (3) the formation of the formate intermediate is already complete by $200 \mathrm{~K}$, way below the temperature at which the first $\mathrm{H}_{2}$ desorption peak is seen in the TPD. This latter conclusion was speculated on but not proven in past reports $[9 ; 12 ; 19]$. Finally, all C 1 s XPS peak intensities start to decrease by $400 \mathrm{~K}$, and are almost gone by $500 \mathrm{~K}$, as $\mathrm{CO}_{2}$ and additional $\mathrm{H}_{2}$ desorb from the surface.

The equivalent O 1s XPS spectra sequence as a function of annealing temperature is reported in Figure 6, for formic acid adsorbed on clean $\mathrm{Cu}(110)$ (left panel) and on an oxygen-saturated $\left(\theta_{\mathrm{O}}\right.$ $=0.62 \mathrm{ML}$ ) surface (right). In this case, the data were fitted to three Gaussian peaks, centered at approximately 530.9, 531.7, and $533.5 \mathrm{eV}$ (detailed listing of these BEs and FWHMs are provided in Table 1). In addition, a summary of the peak intensities, in terms of oxygen-atom monolayers versus annealing temperature, is provided in Figure 7. On clean $\mathrm{Cu}(110)$, adsorption at $150 \mathrm{~K}$ leads to a broad peak that can be deconvoluted into two features of equal intensity $\left(\theta_{\mathrm{O}}=\right.$ $0.56 \mathrm{ML}$ each) centered at 532.1 and $533.6 \mathrm{eV}(\mathrm{FWHM}=1.7$ and $1.6 \mathrm{eV}$, respectively; data not shown), an indication again of adsorbed molecular formic acid with its two non-equivalent oxygen atoms.

A transitional spectrum is observed at $190 \mathrm{~K}$, but by $250 \mathrm{~K}$ the data clearly show the three components listed above, and by $300 \mathrm{~K}$ those are fully developed. The peak at $533.5 \mathrm{eV}$ is most likely due to the remaining molecular formic acid, possibly adsorbed via H-bonding to the first layer (hence the slight shift in $\mathrm{BE}$ ); its coverage in the 350 - $400 \mathrm{~K}$ temperature window amounts to about $0.13 \mathrm{ML}$. We assign the other two features, at 530.9 and $531.7 \mathrm{eV}$, to the formate surface intermediate. These could indicate the formation of two different species. However, 
given that their intensities are equivalent, they may alternatively be due to different chemical environments around the two oxygen atoms of the formate moiety. The adsorption mode of formate species on $\mathrm{Cu}(110)$ has been somewhat controversial, but vibrational data has suggested the existence of an asymmetric monodentate bonding modality [20;21] consistent with our XPS analysis. It should be indicated that previous reports have mentioned that the O 1s XPS signal from these formate species is broad, but have not provided further analysis, as we have done here: the identification of the two peaks for the two oxygen atoms in that intermediate is a new contribution to the understanding of this system. Finally, most of the O 1s XPS signals disappear above $\sim 410 \mathrm{~K}$, as the formate decomposes into $\mathrm{CO}_{2}$ and $\mathrm{H}_{2}$.

The $\mathrm{O} 1 \mathrm{~s}$ XPS data for the case of formic acid on $\mathrm{O} / \mathrm{Cu}(110)$, shown in the right panel of Figure 6, could also be fitted with the same three Gaussian peaks used for the analysis of the data from the clean copper surface, except that the first feature in this case is centered at a slightly lower binding energy, by about $0.4 \mathrm{eV}(530.5 \mathrm{eV}$ instead of $530.9 \mathrm{eV})$, because of the added contribution of the atomic oxygen adsorbed on the $\mathrm{Cu}(110)$ surface (which shows a peak at 529.5 $\mathrm{eV}$ ). Moreover, a further $0.4 \mathrm{eV}$ red shift of that peak is observed between 250 and $300 \mathrm{~K}$, possibly because of the desorption of some water, as seen in the TPD. A steady decrease of its intensity with increasing temperature is seen as well, also likely to be associated with the slow loss of surface oxygen as water, even if that is not evident in the TPD traces. In any case, some of the signal around $530.5 \mathrm{eV}$ must originate from formate species, because such species is evidenced above $300 \mathrm{~K}$ by the peak at $531.7 \mathrm{eV}$. Molecular formic acid is detected too, at 533.5 $\mathrm{eV}$, but its coverage amounts to a small fraction of the total, less than $0.03 \mathrm{ML}$, above $300 \mathrm{~K}$. All signals decrease in intensity above $400 \mathrm{~K}$, as the thermal decomposition highlighted by the 
TPD experiments takes place. Interestingly, only about $0.2 \mathrm{ML}$ of the original atomic oxygen remains on the surface at the end of this temperature sequence; the other $\sim 0.4 \mathrm{ML}$ desorb as water (see Figure 4).

\section{Discussion}

The purpose of this work has been to revisit the chemistry of formic acid on clean and oxygencovered $\mathrm{Cu}(110)$ surfaces, taking advantage of the higher quality of the data that can be acquired in TPD and XPS experiments nowadays compared with what was published several decades ago [10-17]. Much of what was learned in those past studies has been corroborated in our work, but additional observations have also afforded us to better discern among the different decomposition mechanisms that have been discussed in the literature. Among the new observations from the data in this report, it is worth highlighting the detection of $\mathrm{H}_{2}$ desorption in TPD experiments from formic acid on oxygen-covered $\mathrm{Cu}(110)$ at $420 \mathrm{~K}$, concomitantly with the production of $\mathrm{CO}_{2}$ previously reported, and the observation of normal kinetic isotope effects for both decomposition temperature regimes seen above $400 \mathrm{~K}$. We have also carried out a detailed quantitative analysis of the TPD and XPS data to extract new stoichiometric information on the formic acid thermal decomposition reaction.

The decomposition of formic acid on clean $\mathrm{Cu}(110)$ appears quite straightforward. Molecular adsorption at low temperatures is followed by the easy removal of the acidic hydrogen, which desorbs as $\mathrm{H}_{2}$ around $350 \mathrm{~K}$, and by the formation of a surface formate species. Our XPS data 
indicate that some deprotonation is already visible at $150 \mathrm{~K}$, and that it is complete by $200 \mathrm{~K}$. It should be indicated, however, that at that point, and until reaching temperatures above $400 \mathrm{~K}$, the copper surface is not only covered with formate species $\left(\theta_{\mathrm{HCOOads}} \sim 0.25 \mathrm{ML}\right)$, but also contains approximately $0.13 \mathrm{ML}$ of molecular formic acid. Moreover, careful deconvolution of the $\mathrm{O} 1 \mathrm{~s}$ XPS traces has led to the suggestion that either there are two types of formate species on the surface, or, more likely, that the formate adsorbs in an asymmetrical fashion leading to the two oxygen atoms sitting in different chemical environments (past studies did not perform such deconvolution analysis $[11 ; 12 ; 14 ; 15 ; 17])$. The nature of the formate species has been discussed extensively in previous publications. The general consensus has been that it adopts a symmetrical bidentate structure with $\mathrm{C}_{2 \mathrm{v}}$ symmetry, on a bridging site across two adjacent atoms in the $\mathrm{Cu}$ rows of the $\mathrm{Cu}(110)$ surface, but there have nevertheless been suggestions, mainly based on vibrational spectroscopy, that the situation may be more complex than that [14]: Sexton and coworkers detected a new vibrational band at $1640 \mathrm{~cm}^{-1} \mathrm{on} \mathrm{Cu}(100)$ below room temperature that they assigned to a $v_{\text {as }}(\mathrm{C}-\mathrm{O})$ mode from formate species tilted away from the $\mathrm{C}_{2 \mathrm{v}}$ symmetry [43], even though Dubois et al. argued that new vibrational band may be due to the readsorption of formic acid [20], and Bowker et al. also discussed the possibility of the formation of a monodentate species [21]. It should be noted that formic acid tends to form dimers [9], so we suggest that molecular formic acid may form hydrogen bonds with the formate surface species, forcing the latter into a monodentate asymmetric geometry [19]. This would account for both the split in the O 1s XPS signals seen for the formate and the high stability of the $0.13 \mathrm{ML}$ of molecular formic acid that remains on the surface to temperatures above $400 \mathrm{~K}$. Regardless, at approximately $460 \mathrm{~K}$ the formate decomposes into $\mathrm{CO}_{2}$ and $\mathrm{H}_{2}$, and the molecular formic acid desorbs as well. 
The thermal chemistry of formic acid on oxygen-covered $\mathrm{Cu}(110)$ becomes somewhat more complex than on the clean metal. First, deprotonation is now aided by the coadsorbed oxygen, and leads to the formation of $\mathrm{OH}$, not $\mathrm{H}$, surface species. The newly formed $\mathrm{OH}$ surface group disproportionates in several stages to produce water (and adsorbed oxygen atoms), the first stage in a TPD peak around $250 \mathrm{~K}$. Unfortunately, the nature of the formate species in this case cannot be easily established from the XPS data because of interference from the coadsorbed oxygen atoms, but the detection of a strong $\mathrm{O} 1 \mathrm{~s}$ XPS signal at $531.7 \mathrm{eV}$ is suggestive that hydrogen bonding with molecular formic acid may take place here as well. In any case, the most important change seen upon oxygen addition to the surface is the opening of a new thermal decomposition channel at approximately $420 \mathrm{~K}$, in addition to the $460 \mathrm{~K}$ TPD peaks seen on the clean $\mathrm{Cu}(110)$. This change has been quite well documented already [10-16], but not properly explained to date. Below, we attempt to propose a mechanism consonant with the TPD and XPS observations. In the following discussion, we rely heavily on the stoichiometry determined from the measured TPD yields as a function of surface oxygen precoverage, as reported in Figure 4. Emphasis is placed on the changes seen at high oxygen coverages, beyond $\theta_{\mathrm{O}}=0.5 \mathrm{ML}$, as the surface structure transitions from an alternate $-\mathrm{Cu}-\mathrm{O}-\mathrm{Cu}-\mathrm{O}-$ row distribution in the $\mathrm{O}-(2 \times 1)$ layer to a row pairing leading to a $\mathrm{O}-\mathrm{c}(6 \times 2)$ new order $[15 ; 44-46]$.

We begin by discussing the mechanisms put forward by previous research groups in the literature. First, there is the suggestion of the formation of a carbonate surface species advanced by Carley et al. [14]. Those authors could not directly identify such intermediate, however, and made their argument based on a series of indirect stoichiometric calculations that included the 
use of their O 1s XPS signals but that did not account for the potential presence of different oxygen species on the surface (resulting in the broad XPS features they reported), as has been done here; our data do not support this idea. There are no indications of carbonate formation in the UPS [11] or vibrational [19;21] data available either. Based on the evidence available so far, this mechanism appears quite unlikely. An alternative explanation was put forward by Campbell and coworkers where formate surface species disproportionate on the oxygen-covered $\mathrm{Cu}(110)$ surface around $420 \mathrm{~K}$ to produce molecular formic acid and $\mathrm{CO}_{2}$ [12]. This idea was borne out of the inability to detect the coincident production of hydrogen with $\mathrm{CO}_{2}$ in that temperature regime, as expected if simple formate decomposition were to take place. However, our TPD traces in Figures 2 and 3 clearly show that the $420 \mathrm{~K} \mathrm{H}_{2}$ production does indeed take place. It should be also said that, in their experiments, Campbell et al. did not observe the proposed coincident desorption of formic acid either, a fact that they attributed to rapid decomposition of formic acid on the chamber walls. We do see molecular desorption in the $420 \mathrm{~K}$ TPD peak, but the trend of yield versus $\theta_{\mathrm{O}}$ observed for that species does not follow that of $\mathrm{CO}_{2}$ (formic acid production at $420 \mathrm{~K}$ increases with $\theta_{\mathrm{O}}$, whereas the yield for $\mathrm{CO}_{2}$ in the same temperature range is approximately flat), and in any case it only amount to $30 \%$ or less of the $\mathrm{CO}_{2}$ production. Moreover, we also provide clear XPS evidence for the presence of the molecular formic acid adsorbate on the surface starting at much lower temperatures and surviving up to the first (420 K) TPD peak. On the whole, our data are not consistent with the disproportionation mechanism of Campbell and collaborators either. Finally, the group of Bowker have suggested that the lower-temperature desorption state during the decomposition of $\mathrm{HCOOH}$ on the $\mathrm{O}-\mathrm{c}(6 \times 2)$ $\mathrm{O} / \mathrm{Cu}(110)$ surface results from the decomposition of formate species adsorbed in a bilayer arrangement [15]. This is a more feasible explanation that shares some common points with 
ours, but still relies on a relatively static picture of the surface, with separate adsorption states for the formate intermediate during thermal activation. The extensive STM work by the same Bowker group $[27 ; 28 ; 31]$ as well as by others $[26 ; 46]$ clearly shows that this is a very dynamic surface instead.

Next, we elaborate on the interpretation of our TPD data. The first clear observation deriving from the data in Figure 4 is the fact that the total uptake of formic acid first increases when the addition of oxygen to the surface, an observation that has in fact been reported by others in the past $[11 ; 12]$. Much of this increase is matched by the increases in the yields seen for the decomposition products, of $\mathrm{CO}_{2}$ in particular. However, all those trends revert after reaching $\theta_{\mathrm{O}}$ $\sim 0.5 \mathrm{ML}$, beyond which the amount of molecules desorbing from the surface decrease in all cases. Pointedly, there is a one-to-one correspondence between the extra number of $\mathrm{O}$ atoms on the surface past the $\theta_{\mathrm{O}}=0.5$ ML mark, which corresponds to a $\mathrm{O}-(2 \times 1)$ ordered structure $[47$; 48], and the decrease in the initial uptake of formic acid. It would appear that as the surface transitions to the $\mathrm{O}-\mathrm{c}(6 \times 2)$ structure that develops at high oxygen coverages [15; 44-46], the number of sites for the conversion of formic acid to formate species decreases. Since the uptake does increase up to $\theta_{\mathrm{O}}=0.50 \mathrm{ML}$, it is possible that formic acid adsorption requires sites where the oxygen atoms are in the isolated $-\mathrm{Cu}-\mathrm{O}-\mathrm{Cu}-\mathrm{O}-$ rows of the $\mathrm{O}-(2 \times 1)$ structure, and that the doubling of those rows, as it happens as the $\mathrm{O}-\mathrm{c}(6 \mathrm{x} 2)$ structure develops, blocks the copper next to the $\mathrm{O}$ atoms on one of the sides of the rows and consequently eliminates the required surface ensemble for $\mathrm{HCOOH}$ bonding. It is worth pointing out that the presence of some surface oxygen atoms is desirable for formic acid adsorption, since those help with the initial acidic hydrogen atom abstraction (the formic acid uptake does go up with oxygen coverage up to $\theta_{\mathrm{O}}=$ 
$0.5 \mathrm{ML})$; the issue here is that those $\mathrm{O}$ atoms need to be isolated on both sides of the $-\mathrm{Cu}-\mathrm{O}-$ $\mathrm{Cu}-\mathrm{O}-$ rows. We suggest that formate adsorption may still occur via bonding of the oxygen atoms to the copper surface atoms, as on the clean surface [31], but that the formate plane may tilt toward the surface and the remaining hydrogen atom in the formate moiety may form a weak bond to an adjacent $\mathrm{O}$ surface atom. It is also possible for molecular formic acid to hydrogenbond to the first formate layer, as on the clean $\mathrm{Cu}(110)$.

Most of the decreases in total yields of the desorbing products $\left(\mathrm{H}_{2}, \mathrm{H}_{2} \mathrm{O}, \mathrm{CO}_{2}, \mathrm{HCOOH}\right)$ seen with increasing oxygen coverage past the $\theta_{\mathrm{O}}=0.5 \mathrm{ML}$ mark are associated with the $460 \mathrm{~K}$ TPD feature, with all species showing approximately the same trends, and are likely accounted for by the decrease in initial $\mathrm{HCOOH}$ uptake discussed in the previous paragraph. However, the downward trends in yields in the $460 \mathrm{~K}$ peak start at much lower oxygen coverages; it is only that they are compensated by increases in desorption yields in the $420 \mathrm{~K}$ regime that occur up to $\theta_{\mathrm{O}}=0.5 \mathrm{ML}$. Indeed, the $420 \mathrm{~K}$ desorption channel is clearly seen already for $\theta_{\mathrm{O}}=0.4 \mathrm{ML}$ in our data, and according to TPD data from the literature seems to start at $\theta_{\mathrm{O}} \sim 0.25 \mathrm{ML}[12 ; 14]$; only the 460 TPD peaks are seen up to that oxygen coverage. The proposal here is that the 460 $\mathrm{K}$ TPD peaks reflect the formate decomposition pathways already available on the clean $\mathrm{Cu}(110)$ surface, with the initial formation of the formate intermediate being favored and enhanced by the presence of oxygen atoms on the surface.

That leaves us with the need to explain the chemistry that occurs at $420 \mathrm{~K}$ on the $\mathrm{Cu}(110)$ surfaces dosed with high coverages of oxygen atoms. The yields in that TPD feature initially grow, presumably starting at $\theta_{\mathrm{O}} \sim 0.25 \mathrm{ML}$, but then level off beyond $\theta_{\mathrm{O}} \sim 0.5 \mathrm{ML}$. This 
suggests that there may be a kinetic limitation, and that beyond a certain formate/oxygen threshold coverage the surface reverts to its low-oxygen-coverage nature and requires higher temperatures $(460 \mathrm{~K})$ to promote the decomposition of the formate intermediate. Such transition can be further understood in connection with the reduction in oxygen coverage that takes place as hydrogen atoms from the formate intermediate react and form $\mathrm{OH}$ surface groups, and ultimately water (which desorbs). Notice, for instance, that when starting with $\theta_{\mathrm{O}}=0.67 \mathrm{ML}$, which produces a O-c $(6 \times 2)$ ordered structure on the surface, both TPD and XPS data indicate that the final oxygen coverage upon formic acid surface saturation and subsequent thermal activation is approximately $\theta_{\mathrm{O}} \sim 0,2-0.3 \mathrm{ML}$. From that loss, approximately $0.2 \mathrm{ML}$ desorb as water in the $420 \mathrm{~K}$ peak, which means that the remaining formate surface species reacts at $460 \mathrm{~K}$ on a surface that in effect looks like if the experiment would have been started with an initial coverage of about half a monolayer, that is, with the $\mathrm{O}-(2 \times 1)$ structure. The transition between such ordered structures has indeed been shown directly by STM. Our contention is that the thermal chemistry seen for adsorbed formate species at $420 \mathrm{~K}$ on $\mathrm{Cu}(110)$ precovered with oxygen is in essence the same as on clean copper, albeit perhaps facilitated by the ease with which the oxygen atoms can help in the hydrogen abstraction steps (or by weakening the adsorption energy of the formate intermediate), and that the detection of two temperature regimes at 420 and $460 \mathrm{~K}$ in the TPD is a reflection of a kinetic transition in the structure of the $\mathrm{O} / \mathrm{Cu}(110)$ substrate during the course of the temperature ramping in the TPD experiments. According to this model, formate species thermally decompose in a similar way, via hydrogen abstraction to produce $\mathrm{CO}_{2}$, in both cases. 
Some details of this chemistry remain not fully explained. In particular, there is a curious partition in the way the hydrogen atoms extracted from the formic acid are removed from the surface, as $\mathrm{H}_{2}$ and $\mathrm{H}_{2} \mathrm{O}$. As mention above and also reported multiple times in the past, the addition of oxygen to the $\mathrm{Cu}(110)$ surface suppresses the $350 \mathrm{~K} \mathrm{H}_{2}$ peak due to formic acid deprotonation and generates a $\mathrm{H}_{2} \mathrm{O} 250 \mathrm{~K}$ peak instead. However, the stoichiometry of that water production is not what would be expected from a simple switchover in the first elimination step. Specifically, the low-temperature water production splits approximately evenly between the 350 and $420 \mathrm{~K}$ peaks, and those yields grow continuously with oxygen coverage at the expense of the high-temperature $(460 \mathrm{~K})$ peak: at $\theta_{\mathrm{O}}=0.5 \mathrm{ML}$ the $\mathrm{H}_{2} \mathrm{O}$ yields split in an approximately 1:1:6 ratio (for the 250:420:460 K peaks), whereas at $\theta_{\mathrm{O}}=0.62 \mathrm{ML}$ those proportions are about 1:1:2. The stoichiometry does not split evenly between $\mathrm{H}_{2}$ and $\mathrm{H}_{2} \mathrm{O}$ production either: the form in which the $\mathrm{H}$ from $\mathrm{HCOOH}$ decomposition desorbs evolves from all seeing as $\mathrm{H}_{2}$ on the clean $\mathrm{Cu}(110)$ (and up to $\theta_{\mathrm{O}} \leq 0.25 \mathrm{ML}$ ) to the detection of about $1 / 3 \mathrm{H}_{2}$ and $2 / 3 \mathrm{H}_{2} \mathrm{O}$ for $\theta_{\mathrm{O}} \geq 0.5 \mathrm{ML}$. Next, the $\mathrm{H}_{2}$ TPD traces match in shape those for $\mathrm{CO}_{2}$ desorption, but the water peak in the lower temperature $(420 \mathrm{~K})$ regime is smaller and starts at higher temperatures than the rest. Finally, there is a kinetic isotope effect that modifies the relative yields of molecular hydrogen versus water in the low-temperature regime, with a clear relative enhancement in water production, at the expense of hydrogen, with deuterated formic acid. We believe that all these subtle effects may have to do with the disproportionation of $\mathrm{OH}$ surface groups to produce water and with the reversible interconversion between the different oxygencovered copper surface structures, and are not inherent to the thermal chemistry of the adsorbed formate surface species. 


\section{Conclusions}

The thermal chemistry of formic acid on clean and oxygen-predosed $\mathrm{Cu}(110)$ single crystal surfaces was characterized under ultrahigh vacuum by TPD and XPS. On clean $\mathrm{Cu}(110)$, the TPD data indicated that the only decomposition products are molecular hydrogen, seen at 350 and $460 \mathrm{~K}$, and carbon dioxide, which evolves at $460 \mathrm{~K}$ as well. Molecular desorption is also seen, at about $270 \mathrm{~K}$ and with the $\mathrm{H}_{2}$ and $\mathrm{CO}_{2}$ at $460 \mathrm{~K}$. Addition of oxygen to the surface inhibits the low temperature hydrogen and formic acid peaks and leads to the evolution of water instead, at 250, 420, and $460 \mathrm{~K}$. Moreover, a new decomposition pathway opens up at $420 \mathrm{~K}$, also leading to $\mathrm{H}_{2}$ and $\mathrm{CO}_{2}$ (and water and formic acid) production. The decomposition of DCOOD shows the same trends, but with the two main 420 and $460 \mathrm{~K}$ TPD peaks shifting to 440 and $480 \mathrm{~K}$, respectively. A quantitative analysis of the TPD data indicated that the total formic acid uptake increases steadily with oxygen coverage up to $0.5 \mathrm{ML}$, after which it goes down again, mainly because of a decrease in the yields in the high-temperature (460-480 K) regime.

$\mathrm{C}$ 1s XPS data from a saturation layer of formic acid on clean $\mathrm{Cu}(110)$ as a function of annealing temperature was interpreted as the result of the formation of a formate:formic acid mixture on the surface at temperatures as low as $200 \mathrm{~K}$, in a 2:1 ratio. That layer remains the same until reaching temperatures above $400 \mathrm{~K}$, at which point the thermal decomposition seen in the TPD traces leads to the disappearance of virtually all of the C 1s XPS signal. The O 1s XPS traces were deconvoluted to highlight the asymmetric nature of the formate intermediate, possible a monodentate species hydrogen bonded to formic acid on a second layer. Similar species appear 
to form on oxygen-saturated $\mathrm{Cu}(110)$, albeit with different coverages, and some oxygen removal is seen at high temperatures, as water evolves into the gas phase according to the TPD experiments.

Many of the results shown here corroborate or enhance previous reports, but new observations are provided as well. Specifically, desorption of $\mathrm{H}_{2}$ at $420 \mathrm{~K}$ on the oxygen-predosed $\mathrm{Cu}(110)$ surfaces, a controversial point in the past, has been demonstrated. Kinetic isotope effects were also identified upon substitution of $\mathrm{HCOOH}$ with DCOOD. XPS peak fitting afforded the establishment of a threshold temperature for formate formation of $200 \mathrm{~K}$ and the possible identification of an asymmetric surface bonding mode, as mentioned above, and quantitative analysis of the TPD data, including peak fitting, afforded the identification of new trends, including a one-to-one reduction in formic acid uptake for oxygen coverages above half a monolayer, mostly seen in the $460 \mathrm{~K}$ TPD peak. A reaction model has been proposed to interpret these and previous results where formate decomposition always occurs via hydrogen removal and $\mathrm{CO}_{2}$ formation, but where oxygen-assisted hydrogen abstraction is possible at lower $(420 \mathrm{~K})$ temperatures only until enough oxygen has been removed from the surface, via water desorption, to induce a reversion of the surface to a structure associated with lower oxygen coverages, namely until the $\mathrm{O}-\mathrm{c}(6 \times 2)$ structure seen for $\theta_{\mathrm{O}}=0.67 \mathrm{ML}$ transforms into the O(2x1) order corresponding to $\theta_{\mathrm{O}}=0.5 \mathrm{ML}$.

\section{Acknowledgements}


This work was supported by the U.S. Department of Energy, Office of Science, Basic Energy Sciences, Materials Science Division, under Award No. DE-SC0001839.

\section{References}

[1] K. C. Waugh, Catal. Today 15 (1992) 51-75.

[2] F. Studt, M. Behrens, E. L. Kunkes, N. Thomas, S. Zander, A. Tarasov, J. Schumann, E. Frei, J. B. Varley, F. Abild-Pedersen, J. K. Nørskov, R. Schlögl, ChemCatChem 7 (2015) $1105-1111$.

[3] B. A. Peppley, J. C. Amphlett, L. M. Kearns, R. F. Mann, Appl. Catal. A 179 (1999) 31-49.

[4] D. R. Palo, R. A. Dagle, J. D. Holladay, Chem. Rev. 107 (2007) 3992-4021.

[5] D. S. Newsome, Catal. Rev. - Sci. Eng. 21 (1980) 275-281.

[6] C. Ratnasamy, J. P. Wagner, Catal. Rev. 51 (2009) 325-440.

[7] R. Burch, A. Goguet, F. C. Meunier, Appl. Catal. A 409-410 (2011) 3-12.

[8] S. D. Senanayake, D. Stacchiola, J. A. Rodriguez, Acc. Chem. Res. 46 (2013) 1702-1711.

[9] M. R. Columbia, P. A. Thiel, J. Electroanal. Chem. 369 (1994) 1-14.

[10] D. H. S. Ying, J. M. Robert, J. Catal. 61 (1980) 48-56.

[11] M. Bowker, R. J. Madix, Surf. Sci. 102 (1981) 542-565.

[12] F. C. Henn, J. A. Rodriguez, C. T. Campbell, Surf. Sci. 236 (1990) 282-312.

[13] M. Bowker, E. Rowbotham, F. M. Leibsle, S. Haq, Surf. Sci. 349 (1996) 97-110.

[14] A. F. Carley, P. R. Davies, G. G. Mariotti, Surf. Sci. 401 (1998) 400-411.

[15] P. Stone, S. Poulston, R. A. Bennett, N. J. Price, M. Bowker, Surf. Sci. 418 (1998) 71-83. 
[16] T. G. A. Youngs, S. Haq, M. Bowker, Surf. Sci. 602 (2008) 1775-1782.

[17] O. Karis, J. Hasselström, N. Wassdahl, M. Weinelt, A. Nilsson, M. Nyberg, L. G. M. Pettersson, J. Stöhr, M. G. Samant, J. Chem. Phys. 112 (2000) 8146-8155.

[18] M. D. Crapper, C. E. Riley, D. P. Woodruff, A. Puschmann, J. Haase, Surf. Sci. 171 (1986) $1-12$.

[19] B. E. Hayden, K. Prince, D. P. Woodruff, A. M. Bradshaw, Surf. Sci. 133 (1983) 589-604.

[20] L. H. Dubois, T. H. Ellis, B. R. Zegarski, S. D. Kevan, Surf. Sci. 172 (1986) 385-397.

[21] M. Bowker, S. Haq, R. Holroyd, P. M. Parlett, S. Poulston, N. Richardson, J. Chem. Soc., Faraday Trans. 92 (1996) 4683-4686.

[22] I. Nakamura, H. Nakano, T. Fujitani, T. Uchijima, J. Nakamura, J. Vac. Sci. Technol., A 17 (1999) 1592-1595.

[23] H. Nakano, I. Nakamura, T. Fujitani, J. Nakamura, J. Phys. Chem. B 105 (2001) 13551365.

[24] S. M. York, S. Haq, K. V. Kilway, J. M. Phillips, F. M. Leibsle, Surf. Sci. 522 (2003) 3446.

[25] K. Inoue, F. Wakabayashi, K. Domen, Catal. Lett. 142 (2012) 1197-1201.

[26] S. Haq, F. M. Leibsle, Surf. Sci. 375 (1997) 81-90.

[27] S. Poulston, R. A. Bennett, A. H. Jones, M. Bowker, Phys. Rev. B 55 (1997) 12888-12891.

[28] S. Poulston, A. Jones, R. A. Bennett, M. Bowker, Surf. Sci. 377-379 (1997) 66-70.

[29] R. A. Bennett, S. Poulston, M. Bowker, J. Chem. Phys. 108 (1998) 6916-6922.

[30] M. Bowker, R. A. Bennett, S. Poulston, P. Stone, Catal. Lett. 56 (1998) 77-83.

[31] M. Bowker, S. Poulston, R. A. Bennett, P. Stone, A. H. Jones, S. Haq, P. Hollins, J. Mol. Catal. A 131 (1998) 185-197. 
[32] S. L. Silva, A. A. Patel, T. M. Pham, F. M. Leibsle, Surf. Sci. 441 (1999) 351-365.

[33] S. J. Harrington, K. V. Kilway, D. M. Zhu, J. M. Phillips, F. M. Leibsle, Surf. Sci. 600 (2006) 1193-1200.

[34] J. A. Rodriguez, C. T. Campbell, Surf. Sci. 183 (1987) 449-468.

[35] J. R. B. Gomes, J. A. N. F. Gomes, Surf. Sci. 432 (1999) 279-290.

[36] N. Atodiresei, K. Schroeder, S. Blügel, Phys. Rev. B 75 (2007) 115407.

[37] F. Zaera, Coord. Chem. Rev. 257 (2013) 3177-3191.

[38] T. J. Knisley, T. C. Ariyasena, T. Sajavaara, M. J. Saly, C. H. Winter, Chem. Mater. 23 (2011) 4417-4419.

[39] L. C. Kalutarage, S. B. Clendenning, C. H. Winter, Chem. Mater. 26 (2014) 3731-3738.

[40] G. Dey, S. D. Elliott, RSC Adv. 4 (2014) 34448-34453.

[41] F. Zaera, J. Vac. Sci. Technol. A 7 (1989) 640-645.

[42] T. Kim, Y. Yao, J. P. Coyle, S. T. Barry, F. Zaera, Chem. Mater. 25 (2013) 3630-3639.

[43] B. A. Sexton, Surf. Sci. 88 (1979) 319-330.

[44] G. Dorenbos, M. Breeman, D. O. Boerma, Phys. Rev. B 47 (1993) 1580-1588.

[45] W. Liu, K. C. Wong, K. A. R. Mitchell, Surf. Sci. 339 (1995) 151-158.

[46] Q. Liu, L. Li, N. Cai, W. A. Saidi, G. Zhou, Surf. Sci. 627 (2014) 75-84.

[47] F. Jensen, F. Besenbacher, E. Laegsgaard, I. Stensgaard, Phys. Rev. B 41 (1990) 1023310236.

[48] P. R. Davies, M. Bowker, Catal. Today 154 (2010) 31-37. 
Table 1. Parameters used in the fitting of the XPS spectra in Figures $5(\mathrm{C} 1 \mathrm{~s})$ and $6(\mathrm{O}$ 1s) to a set of Gaussian peaks, two for the C 1s data and three for the O 1s traces. Provided are the values used for the binding energies (BE) and full-with-at-half-maximum (FWHM, or $\Delta$ ) of each fitted peak. Most of these parameters were held constant across the set of spectra, letting only the intensities be adjusted, unless significant deviations between the data and the fits were observed.

\begin{tabular}{|c|c|c|c|c|c|c|c|c|c|c|c|c|c|c|c|c|}
\hline \multirow[b]{4}{*}{$\mathrm{T} / \mathrm{K}$} & \multicolumn{10}{|c|}{ 2.0 L Formic Acid on Clean $\mathrm{Cu}(110)$} & \multirow{2}{*}{\multicolumn{6}{|c|}{$\frac{2.0 \mathrm{~L} \text { Formic Acid on } 0.67 \mathrm{ML} \mathrm{O} / \mathrm{Cu}(110)}{\mathrm{O} 1 \mathrm{~s}}$}} \\
\hline & \multicolumn{4}{|c|}{$\mathrm{C} 1 \mathrm{~s}$} & \multicolumn{6}{|c|}{$\mathrm{O} 1 \mathrm{~s}$} & & & & & & \\
\hline & \multicolumn{2}{|c|}{ Formate } & \multicolumn{2}{|c|}{ Formic Acid } & \multicolumn{2}{|c|}{ Formate-1 } & \multicolumn{2}{|c|}{ Formate-2 } & \multicolumn{2}{|c|}{ Formic Acid } & \multicolumn{2}{|c|}{ Formate-1 } & \multicolumn{2}{|c|}{ Formate-2 } & \multicolumn{2}{|c|}{ Formic Acid } \\
\hline & $\mathrm{BE} / \mathrm{eV}$ & $\Delta / \mathrm{eV}$ & $\mathrm{BE} / \mathrm{eV}$ & $\Delta / \mathrm{eV}$ & $\mathrm{BE} / \mathrm{eV}$ & $\Delta / \mathrm{eV}$ & $\mathrm{BE} / \mathrm{eV}$ & $\Delta / \mathrm{eV}$ & $\mathrm{BE} / \mathrm{eV}$ & $\Delta / \mathrm{eV}$ & $\mathrm{BE} / \mathrm{eV}$ & $\Delta / \mathrm{eV}$ & $\mathrm{BE} / \mathrm{eV}$ & $\Delta / \mathrm{eV}$ & $\mathrm{BE} / \mathrm{eV}$ & $\Delta / \mathrm{eV}$ \\
\hline $\mathrm{O} / \mathrm{Cu}$ & & & & & & & & & & & 530.4 & 1.5 & 531.8 & 2.8 & & \\
\hline 150 & 286.6 & 2.5 & 289.6 & 2.5 & & & 532.1 & 1.7 & 533.6 & 1.6 & & & & & & \\
\hline 190 & & & & & & & & & & & 530.5 & 2.2 & 531.7 & 2.5 & 533.5 & 2.3 \\
\hline 200 & 287.9 & 2.2 & 289.8 & 1.8 & & & 531.7 & 1.6 & 533.2 & 2.6 & & & & & & \\
\hline 250 & 287.5 & 2.0 & 289.4 & 1.6 & 530.9 & 1.1 & 531.7 & 1.6 & 533.3 & 2.6 & 530.5 & 2.2 & 531.7 & 2.5 & 533.5 & 2.3 \\
\hline 300 & 287.6 & 2.0 & 290.1 & 1.8 & 530.6 & 1.5 & 531.5 & 1.5 & 533.2 & 2.2 & 530.1 & 2.2 & 531.7 & 2.5 & 533.5 & 2.3 \\
\hline 350 & & & & & 530.6 & 1.5 & 531.5 & 1.5 & 533.1 & 2.0 & 530.1 & 2.2 & 531.5 & 2.5 & 533.1 & 2.3 \\
\hline 400 & 287.4 & 1.8 & 290.1 & 1.8 & & & & & & & & & & & & \\
\hline 410 & & & & & 530.6 & 1.5 & 531.5 & 1.5 & 533.1 & 2.0 & 530.1 & 2.2 & 531.5 & 2.5 & 533.1 & 2.3 \\
\hline 500 & 288.2 & 2.0 & 290.8 & 1.8 & 530.6 & 1.5 & 531.5 & 1.5 & 532.9 & 2.0 & & & & & & \\
\hline
\end{tabular}




\section{Figure Captions}

Figure 1. Temperature programmed desorption (TPD) data from $2.0 \mathrm{~L}$ of $\mathrm{HCOOH}$ adsorbed on a clean $\mathrm{Cu}(110)$ surface at $190 \mathrm{~K}$. Shown are the traces obtained for (from bottom to top): $2,12,16,17,18,28,44,45$, and 46 amu.

Figure 2. TPD from 2.0 L of $\mathrm{HCOOH}$ on $\mathrm{Cu}(110)$ as a function of oxygen precoverage. Shown are the sequences for the desorption of: $\mathrm{H}_{2}$ (2 mu, left panel), $\mathrm{H}_{2} \mathrm{O}$ (18 amu, second from left), $\mathrm{CO}_{2}$ (44 amu, second from right), and $\mathrm{HCOOH}$ (46 amu, right).

Figure 3. Comparison of TPD spectra for $2.0 \mathrm{~L}$ of DCOOD (dark traces) versus HCOOH (light traces) adsorbed on $\mathrm{Cu}(110)$, clean (left panel) and after predosing 0.50 (center) and 0.67 (right) ML of atomic oxygen. Traces are shown in each panel for (from bottom to top): molecular hydrogen/deuterium (2/4 amu), normal/deuterated water $(18 / 20$ amu), molecular normal/deuterated formic acid (46/48 amu), and carbon dioxide (44 $\mathrm{amu})$.

Figure 4. TPD yields from 2.0 L of either $\mathrm{HCOOH}$ or DCOOD adsorbed on $\mathrm{Cu}(110)$ as a function of oxygen precoverage. Three panels are provided, summarizing the data for the total yields (left panel) as well as those from the two main TPD peaks at 420/440 (low-T peak, center) and 460/485 (high-T peak, right) K. Data are provided for all the main desorbing species, namely, hydrogen/deuterium (solid/open squares), water (circles), carbon dioxide (upward pointing triangles), formic acid (downward pointing triangles), and total (double circles). 
Figure 5. C 1s X-ray photoelectron spectroscopy (XPS) data from 10.0 L of $\mathrm{HCOOH}$ adsorbed at $150 \mathrm{~K}$ on clean $\mathrm{Cu}(110)$ as a function of annealing temperature. Left: raw data (dots) and fits to Gaussian peaks (solid lines). Right: carbon surface coverages estimated from the areas under the C 1s XPS peaks.

Figure 6. O 1s XPS data from 2.0 L of DCOOD adsorbed on clean (left panel) and oxygenprecovered $\left(\theta_{\mathrm{O}}=0.62 \mathrm{ML}\right.$, right $) \mathrm{Cu}(110)$ surfaces as a function of annealing temperature. Shown are the raw data (dots) as well as the fits to three Gaussian peaks (solid lines).

Figure 7. Oxygen coverages, in terms of monolayers of atomic oxygen, estimated from the data in Figure 6, for 2.0 L of DCOOD adsorbed on clean (left panel) and oxygen-saturated (right) $\mathrm{Cu}(110)$. Data are summarized for the three Gaussian peaks fitted to the raw data, centered at approximately $530.9 / 530.5,531.7$, and $533.5 \mathrm{eV}$, respectively, as well as for the total. The first two features are associated with an asymmetric form of adsorbed formate species (with a component from atomic oxygen in the $530.5 \mathrm{eV}$ values for the $\mathrm{O} / \mathrm{Cu}(110)$ case), whereas the latter is identified with molecular formic acid. 


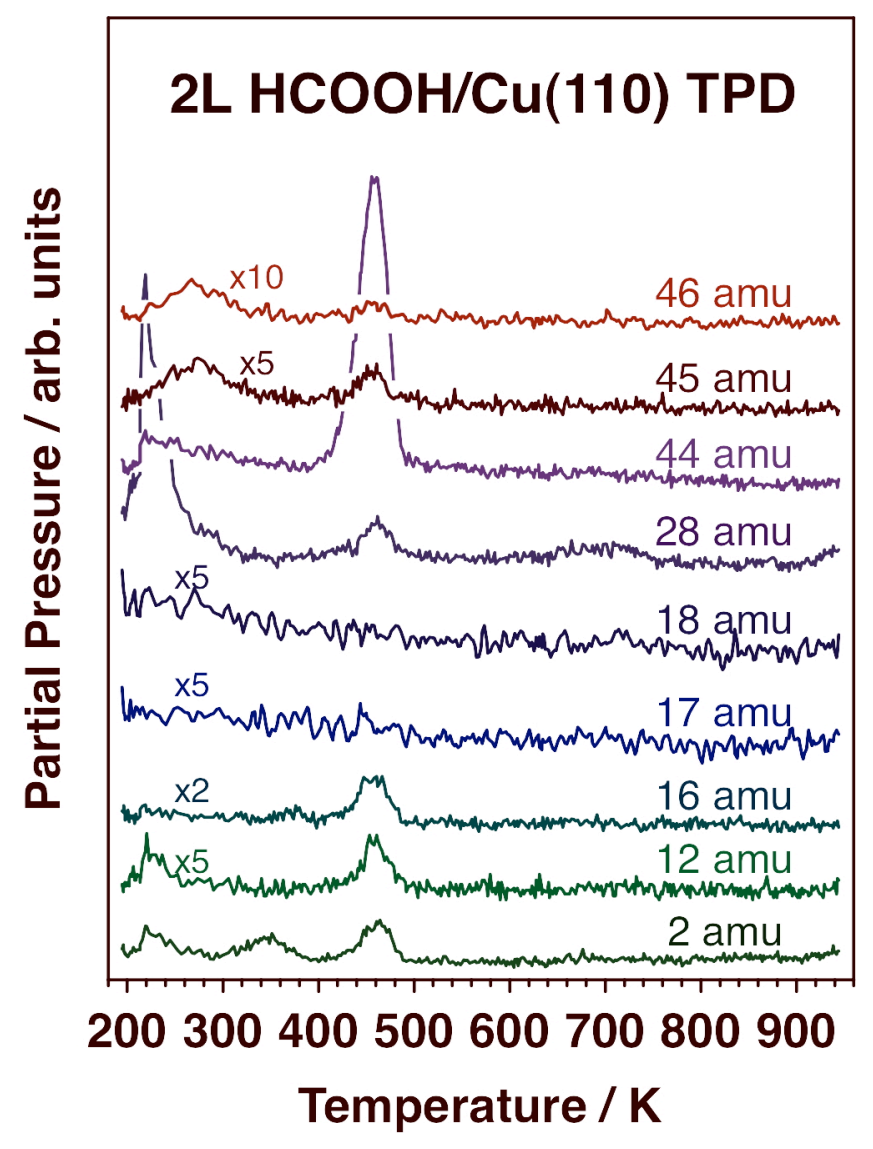

Figure 1 


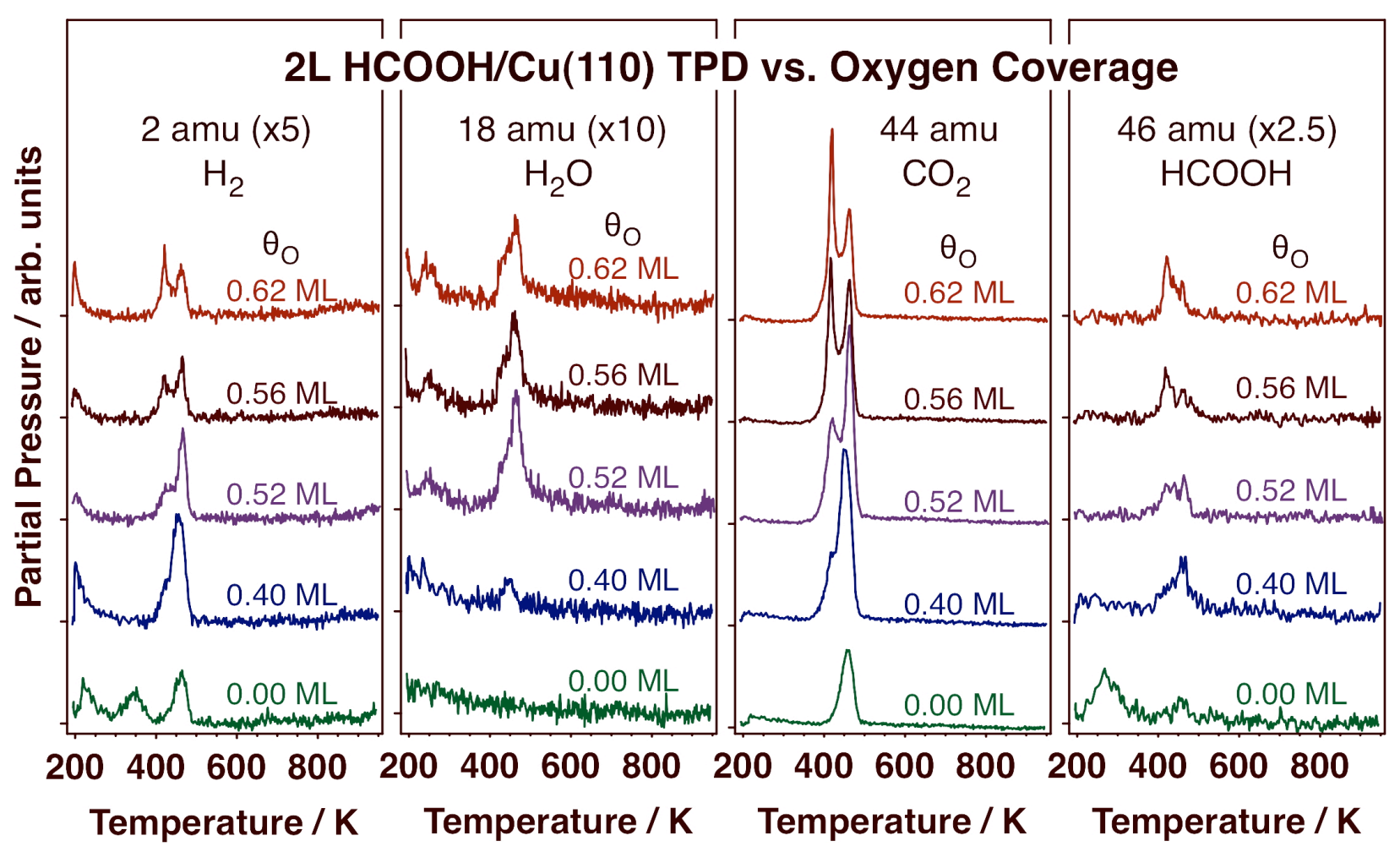

Figure 2 


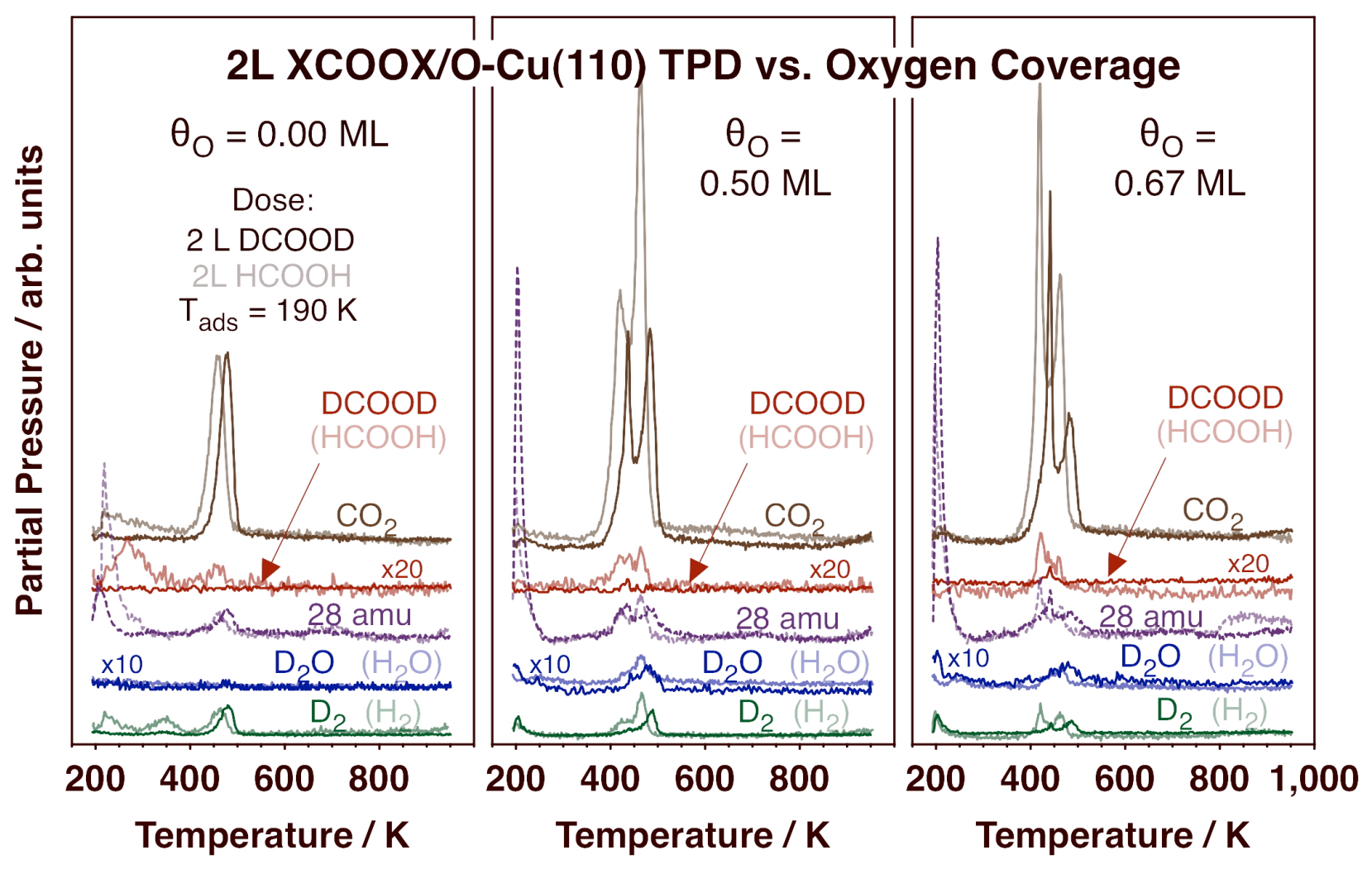

Figure 3 


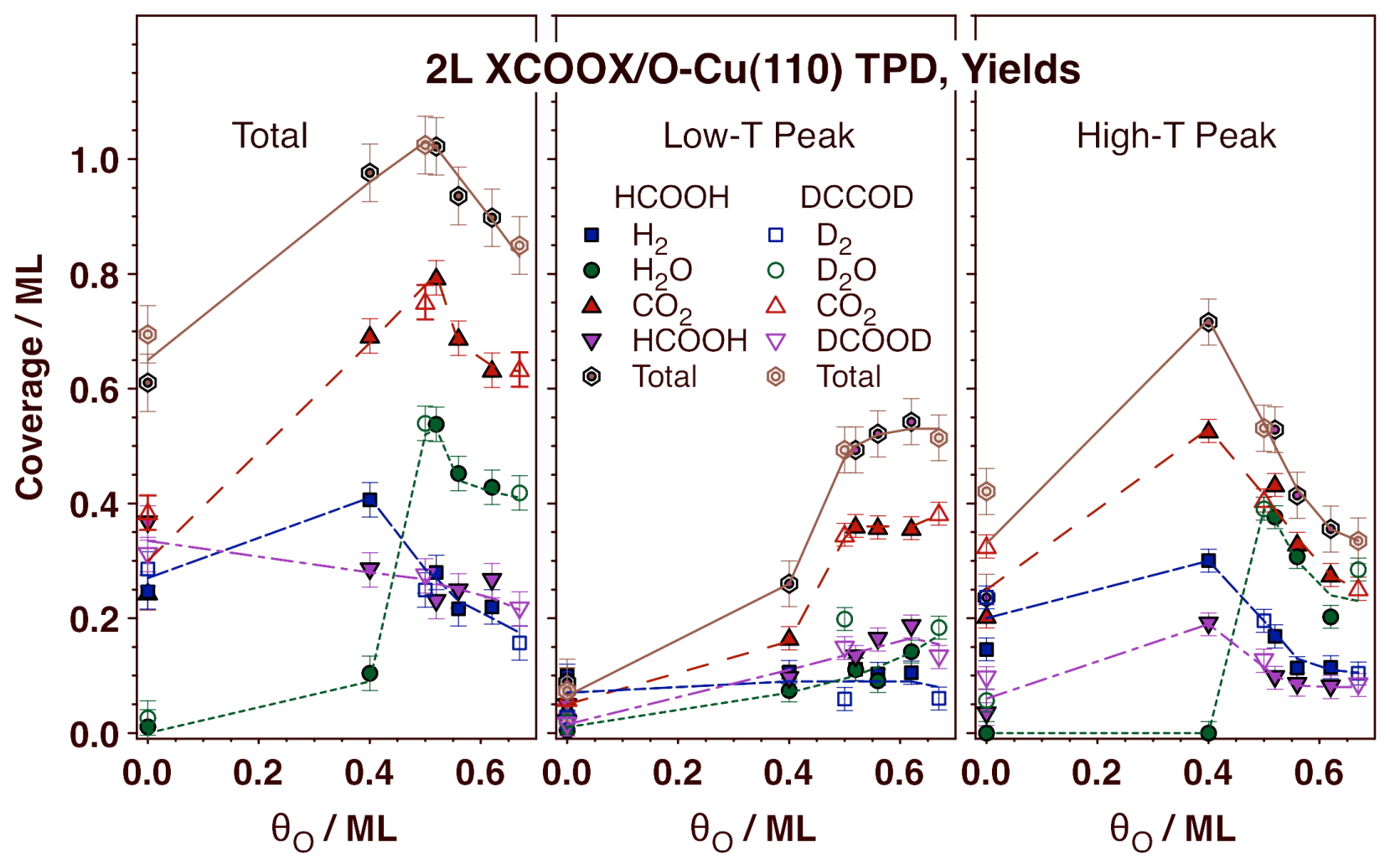

Figure 4 


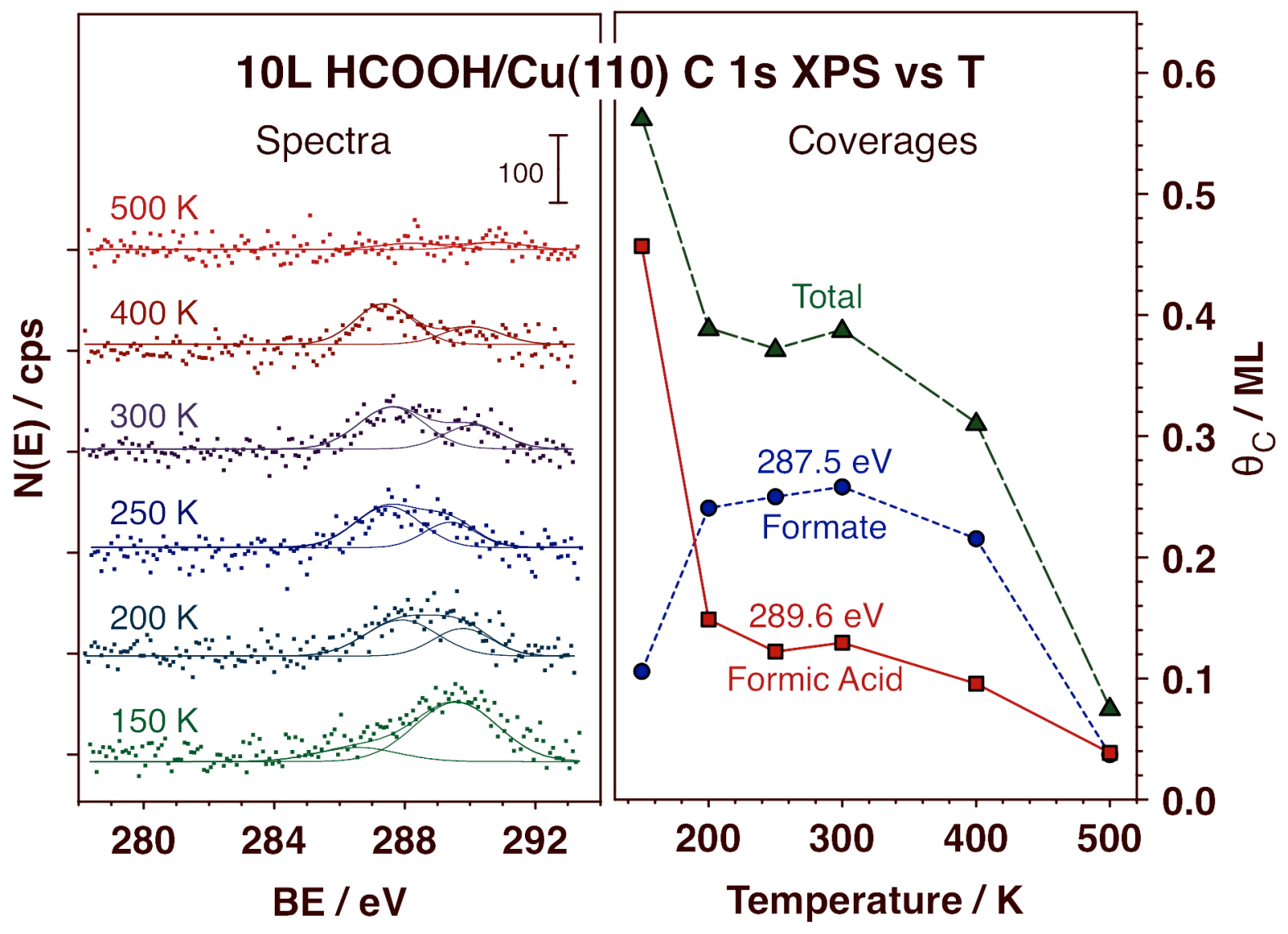

Figure 5 


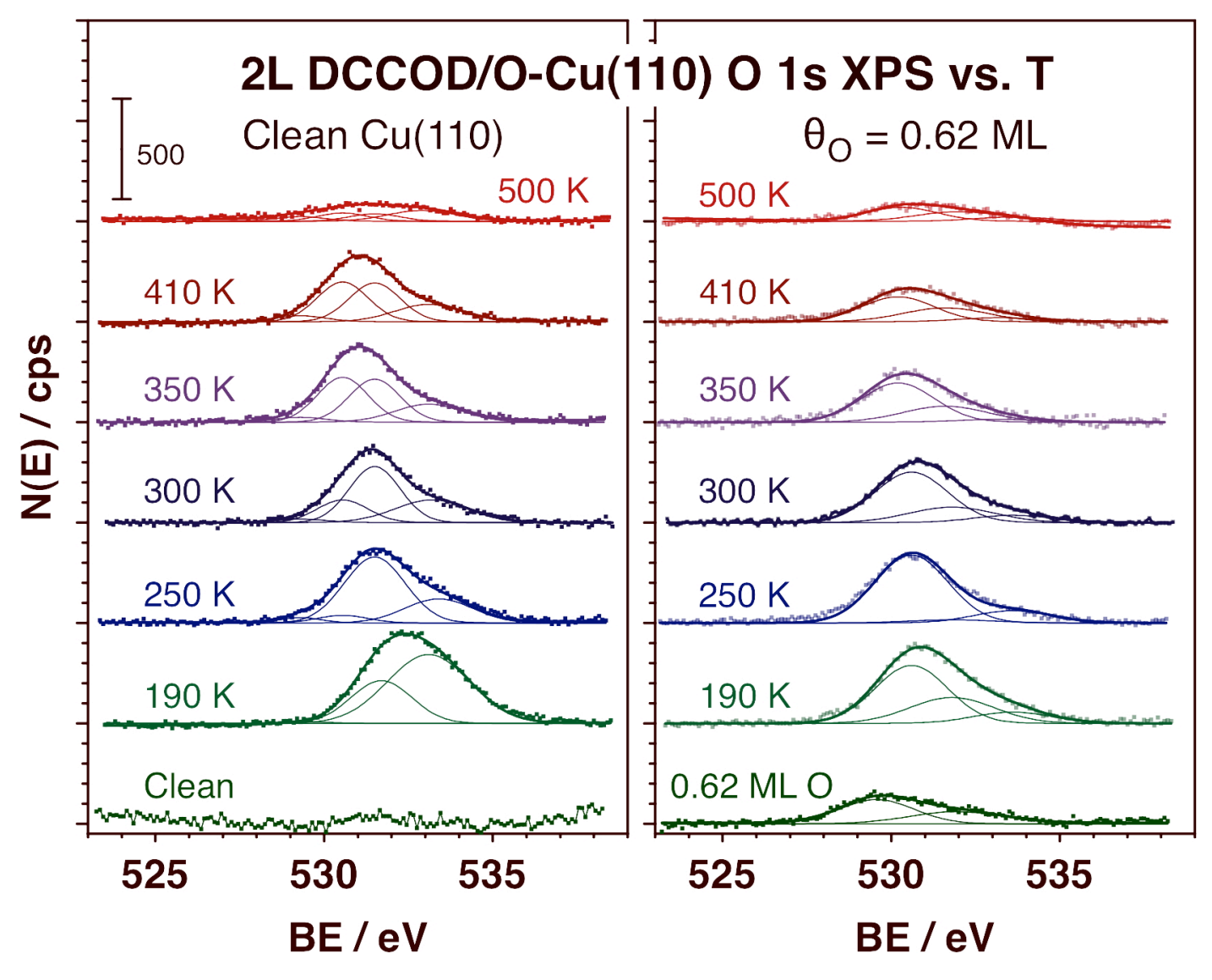

Figure 6 


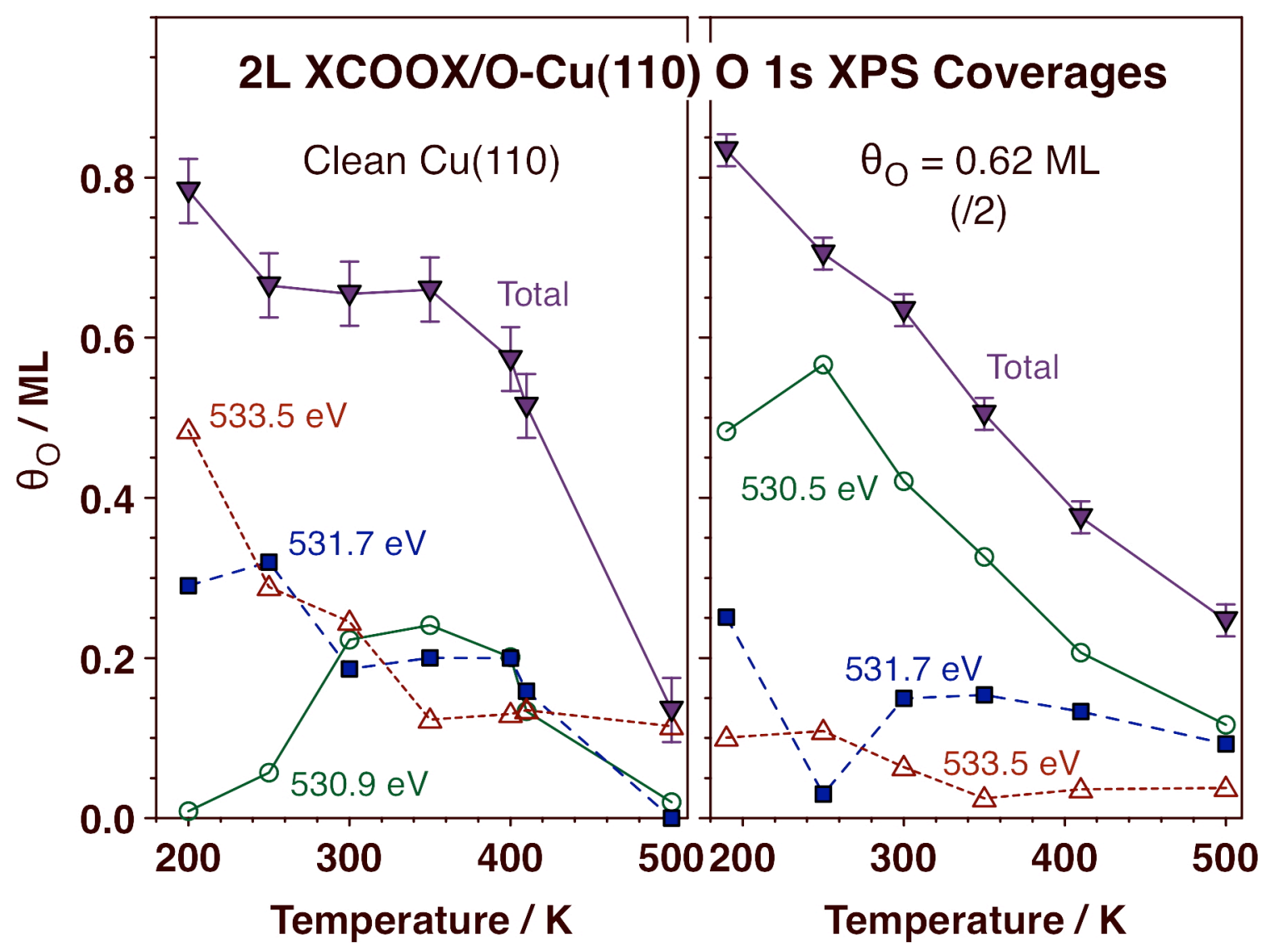

Figure 7 


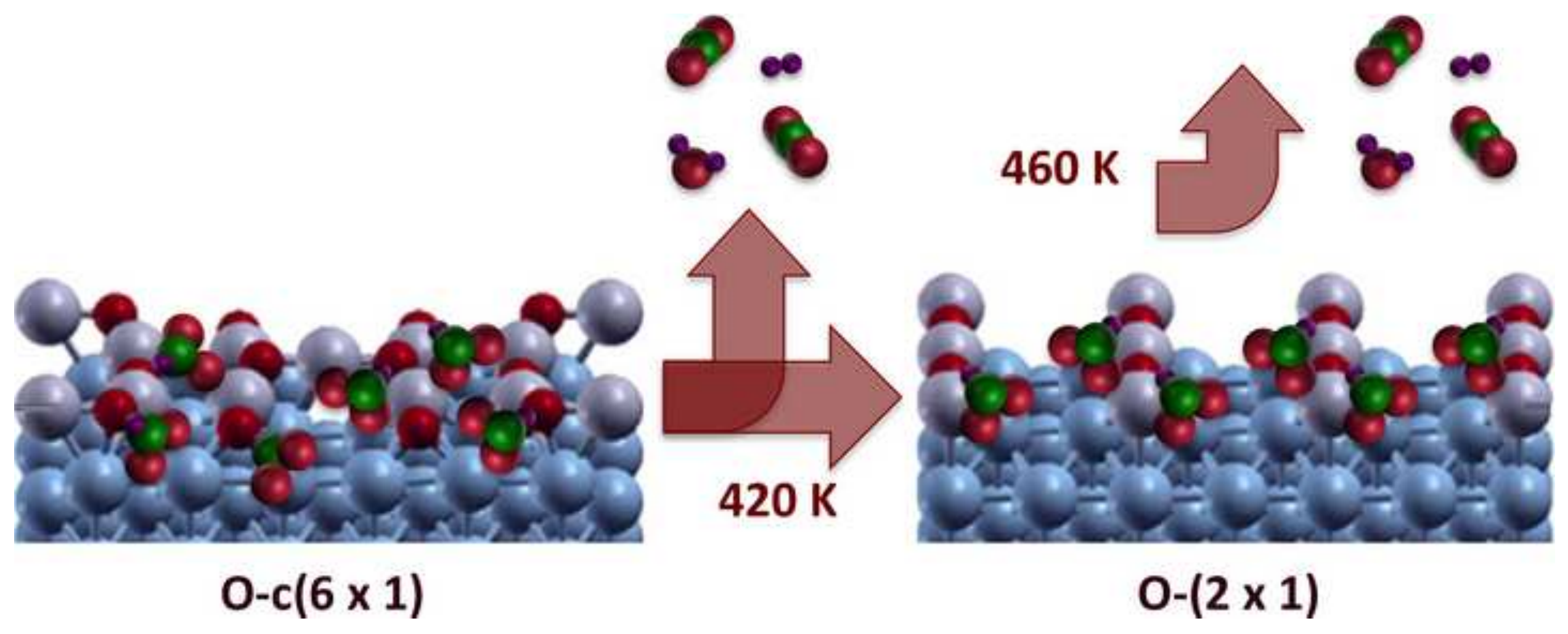

